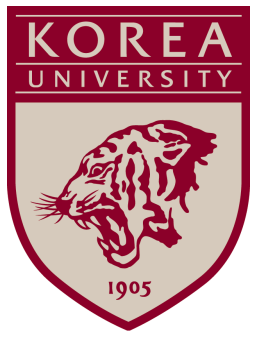

Discussion Paper Series

No. 1303

Nov 2013

Security bid auctions for agency contracts

\author{
Byoung Heon Jun and Elmar G. Wolfstetter
}

The Institute of Economic Research - Korea University

Anam-dong, Sungbuk-ku, Seoul, 136-701, South Korea, Tel: (82-2) 3290-1632, Fax: (82-2) 928-4948

Copyright (C) 2013 IER. 


\title{
Security bid auctions for agency contracts*
}

\author{
Byoung Heon Jun ${ }^{\dagger}$ \\ Korea University, Seoul \\ Department of Economics
}

\author{
Elmar G. Wolfstetter \\ Humboldt-University at Berlin and \\ Korea University, Seoul
}

January 2012

Revised October 2013

\begin{abstract}
A principal uses security bid auctions to award an incentive contract to one among several agents in the presence of hidden action and hidden information. Securities range from cash to equity and call options. "Steeper" securities are better surplus extractors that narrow the gap between the two highest valuations, yet reduce effort incentives. In view of this trade-off, a hybrid share auction that includes a (possibly negative) cash reward to the winner, a minimum share, and an option to call a fixed wage contract, tends to outperform all other auctions, although it it is not an optimal mechanism. However, by adding output targets to hybrid share auctions one can (arbitrary closely) implement the optimal mechanism.
\end{abstract}

KEYWORDS: Auctions and security design, agency problems, mechanism design.

JEL Classifications: D21, D43, D44, D45.

\section{Introduction}

If a risk neutral principal deals with a risk neutral and sufficiently wealthy agent whose effort is unobservable, the optimal contract is a franchising contract. There, the agent becomes full residual claimant in exchange for a take-it-or-leave-it cash payment. ${ }^{1}$ This is true even if the agent's ability is unknown.

If the principal can recruit the agent from a pool of agents whose abilities are unknown, he can do better by replacing the take-it-or-leave-it offer by a standard auction that awards the contract to the highest bidder.

If output is contractible, the principal can do even better by using a contingent payment auction in which cash bids are replaced by bidding with securities. However, such auction formats may adversely affect effort incentives.

\footnotetext{
*We would like to thank Cuihong Fan, Andrzej Skrzypacz, the associate editor, and two anonymous referees for detailed comments. Research support by the National Research Foundation of Korea funded by the Korean Government (NRF-2010-330-B00085), the Deutsche Forschungsgemeinschaft (DFG), SFB Transregio 15, "Governance and Efficiency of Economic Systems", and the National Natural Science Foundation of China (Grant: 71371116) is gratefully acknowledged.

${ }^{\dagger}$ Email: bhjun@korea.ac.kr

${ }^{\ddagger}$ Institute of Economic Theory I, Humboldt University at Berlin, Spandauer Str. 1, 10178 Berlin, Germany, Email: wolfstetter@gmail.com

${ }^{1}$ If the agent is risk averse, the optimal contract exhibits profit sharing (the classical reference is Holmstrœm, 1979), and if the agent cannot make advance payments and is subject to limited liability, it is a bonus contract (Innes, 1990).
} 
The present paper explores the profitability of cash versus security bid auctions ranging from equity (share) to call option auctions for agency contracts in the presence of hidden action and hidden information. These auction formats differ in their ability to extract surplus and implement efficient effort. For example, cash auctions give the agent the full profit, and thus exhibit the strongest possible effort incentives. However, they are weak in extracting surplus, because the principal can extract only the second highest expected profit. Whereas a call option auction, that gives the principal the right to become residual claimant in exchange for a fixed strike price, extracts the full surplus, yet completely lacks effort incentives.

Our main finding is that a hybrid equity or share auction that includes a cash transfer to the winner, a minimum share, and an option to call a fixed wage contract, tends to be the most profitable auction format for the principal, because it manages to strike the best balance between effort incentives and surplus extraction. ${ }^{2}$ However, it is not an optimal mechanism. We then add output targets and show that the thus generalized hybrid share auction can arbitrary closely implement the optimal mechanism.

Share auctions have been introduced by Hansen (1985) who showed that they can extract more surplus than standard cash auctions, provided the winner's valuation is verifiable ex post. One may interpret this finding as an implication of the "linkage principle" according to which linking the price to a variable that is correlated with bidders' private information tends to lower bidders' information rents (see Milgrom, 1987). Later, Crémer (1987) pointed out that by adding small cash transfers to all bidders, share auctions may, paradoxically, achieve full surplus extraction. ${ }^{3}$

In the recent literature, contingent payment auctions have been revived and extended by de Marzo, Kremer, and Scrzypacz (2005) . They consider a larger class of security bid auctions and rank them according to their capacity to extract surplus. In particular, they introduce the concept of "steepness", which partially orders securities, and show that surplus extraction increases in steepness. ${ }^{5}$ Essentially, the equilibrium price of a security bid auction with a steeper security responds more strongly to the winner's valuation. The standard cash auction has the lowest steepness, because the equilibrium price reflects only the second highest valuation and thus cannot extract the gap between the highest and the second highest valuation. In turn, the steepest security is the call option, which entitles the auctioneer to the valuation of the winner in exchange for a fixed price.

Che and Kim (2010) commented on DeMarzo et al. (2005), pointing out that steepness of securities is only indicative of profitability if the considered security bid auctions make the same selection of the winner. In the presence of adverse selection, this is not assured, and the cash auction can make a better selection and yield higher expected profits than the steeper equity (share) or call option auctions.

In the present paper we analyze security bid auctions in the presence of both hidden information and hidden action. We show that the performance of security bid auctions hinges upon their power of surplus extraction and the implied effort incentives. As in DeMarzo et al. (2005), the steeper securities are better surplus extractors, yet this applies only contingent on a given choice of effort. However, the steeper securities dilute effort incentives, and when the choice of effort is made

\footnotetext{
${ }^{2}$ Similar auction formats have been observed in takeover bidding, for example in the takeover of "GE Insurance" in the year 2005 (see Boyle, 2005).

${ }^{3}$ Samuelson (1987) commented that adverse selection or moral hazard may interfere with surplus extraction.

${ }^{4}$ See also Board (2007) and Rhodes-Kropf and Viswanathan (2005) and the survey by Skrzypacz (2013).

${ }^{5}$ This result assumes that valuations are affiliated (if they are stochastically dependent). Recently, Abhishek et al. (2013) proposed a stronger notion of steepness that extends the relationship between steepness and revenue to weaker stochastic order assumptions such as monotone likelihood or first-order stochastic dominance and risk aversion.
} 
endogenous, the generalized share or equity auction, that includes a cash reward to the winner, tends to outperform the less "steep" cash/debt and the "steeper" call option auctions.

Even though the generalized share auction is highly profitable, it is not an optimal mechanism. This is due to the fact that, unlike security bid auctions, the optimal mechanism makes use of output targets. This suggests that the profitability of security bid auctions can be increased by adding output targets. We confirm this conjecture and construct a generalized hybrid share auction that implements the optimal mechanism.

Our model applies to a large range of agency problems with competition, ranging from labor contracts, the sale of a product innovation to entrepreneurs who compete for the exclusive use of this innovation, venture capital financing, government licensing, franchising and other forms of subcontracting, to mergers and acquisitions.

Our analysis also sheds light on the full surplus extraction paradox posed by Crémer (1987) because we show that a share auction can only implement low effort and full surplus extraction, but cannot implement high effort and full surplus extraction, even if one adds a cash payment to the winner, a minimum share, and an option to call a wage contract if no bids are forthcoming.

In a related, independent paper Kogan and Morgan (2010) also incorporate moral hazard into the security bids framework. Unlike in our analysis, in their model effort and agents' type enter in a multiplicative fashion. Whereas they focus on evaluating the performance of equity auctions compared to the debt auction both theoretically and experimentally, the focus of our analysis is to generalize security bid auctions with the intention to close the gap between the profitability of security bid auctions and the optimal mechanism.

The plan of the paper is as follows: In Section 2 we state the model and basic assumptions. In Section 3 we solve the bidding games for different security bid auctions. In Section 4 we generalize the share or equity auction by adding a cash reward or payment to the winner and show that this makes it possible to either increase or reduce share bids, which affects effort incentives, and characterize the optimal generalized share auction. In Section 5 we analyze hybrid cash and share auctions which further fine-tune the cash and generalized share auctions, by adding a minimum price or minimum share and an option to call a fixed wage contract in the event when no bids are forthcoming. In Section 6 we rank the different security bid auctions according to their profitability for the principal. In Section 7 we characterize the optimal mechanism, and in Section 8 show that by adding output targets to hybrid share auctions one can implement the optimal mechanism. In Section 9 we explore some implications of adding uncertainty and limited liability and close in Section 10 with a brief discussion.

\section{Model}

A principal wants to award an incentive contract to one of $n \geq 2$ potential agents, using a security bid auction.

Agents differ in their ability to generate revenue. Agents know their own ability, measured by a productivity index $x \in[0,1]$, but not that of others. They are subject to a production function that maps their effort and productivity into their output.

Output is observable and verifiable, but effort is not observable ("hidden action"), which gives rise to an agency problem. 
The principal awards incentive contracts - ranging from franchising, to fixed-wage and standard principal-agent sharing contracts - and employs one of the following Vickrey style auction rules in which bids are financial securities:

1. Standard (cash) auction: bidders offer cash payments in exchange for becoming the residual claimant; the highest bidder wins and pays the second highest bid.

2. Call option auction: bidders offer call options on their output; the bidder who offers the lowest strike price wins; if the principal exercises the winning option, he gets the winner's output and pays the second-lowest strike price.

3. Equity (share) auction: bidders offer output shares; the bidder who offers the highest share wins and pays the second highest share of his output (and possibly collects a cash reward for the winner which may be positive or negative).

4. Hybrid cash and hybrid share auctions that add a minimum price or share and an option to call a fixed wage contract if no bids have been submitted.

5. Generalized hybrid share auctions that prescribe output targets.

The timing of the game is as follows: 1) bidders (agents) draw their productivity index, which is their private information, and then simultaneously make their bids; 2 ) the auctioneer (principal) selects the winner; 3 ) the winning bidder chooses his effort; 4) output is observed, and the auctioneer collects payments, if any. The equilibrium concept is that of a subgame perfect Nash equilibrium.

The following simplifying assumptions are made.

All parties are risk neutral. The production function, $\phi(x, e):=x+e$, is additive in the productivity index, $x$, and effort, $e{ }^{6}$ Effort is either high $(H)$ or low $(L), e_{H}>e_{L}>0$, and the corresponding cost of effort is $c_{H}>c_{L}>0$, with $\Delta e:=e_{H}-e_{L}>c_{H}-c_{L}=: \Delta c$, assuring that $e_{H}$ is the efficient choice for all $x .^{7}$ Bidders' productivity index (to which we also refer as bidders' type) is an i.i.d. random variable, drawn from the continuously differentiable distribution function $F:[0,1] \rightarrow[0,1]$ with positive p.d.f. $f$ everywhere (symmetric independent private values model) that exhibits logconcavity of the reliability function, $1-F(x)$ (monotone increasing hazard rates).

We denote the $k$-th largest order statistic of a sample of i.i.d. random variables with sample size $n$ by $X_{(k: n)}$ (and by $X_{(k)}$ if the sample size is clear from the context), its p.d.f. by $f_{(k: n)}$, the joint p.d.f. of the highest and the second highest order statistic by $f_{(12)}(x, y)$ (for $x>y$ ), and the c.d.f. of $X_{(1: n-1)}$ by $G(x):=F(x)^{n-1}$. As a general rule, random variables are denoted by capital and realizations by lower case letters.

\section{Equilibrium of standard security bid auctions}

We now characterize the equilibrium strategies and payoffs of the above stated security bid auctions. $^{8}$

\footnotetext{
${ }^{6}$ In Section 9 we explore some implications of adding uncertainty and limited liability, and in the Discussion we sketch briefly some changes that occur if one replaces the additive by a multiplicative production function.

${ }^{7}$ Our analysis easily generalizes to continuum of effort choices combined with a quadratic cost function. This indicates that our assumption of binary effort is not restrictive.

${ }^{8}$ In the following we present the unique symmetric equilibria. As is well-known, second-price auctions have a multitude of asymmetric equilibria which are however not very meaningful and can be eliminated by equilibrium refinements such as trembling-hand perfection.
} 
Proposition 1 (Cash auction). In equilibrium the winner chooses high effort $e=e_{H}$, and each bidder bids the net profit:

$$
b_{c}(x)=x+e_{H}-c_{H} .
$$

Hence, the highest type is selected as a winner. The principal's equilibrium expected revenue is

$$
\Pi^{c}=E\left(X_{(2: n)}\right)+e_{H}-c_{H} .
$$

Proof. Because the winner is residual claimant he has undiluted incentives and chooses the efficient effort level, $e_{H}$. Given this effort strategy, the asserted bid strategy is obviously a (weakly) dominant strategy.

We mention that, in the present context, the same result applies to debt auctions, where bidders offer IOU's in exchange for becoming the residual claimant and the bidder with the highest offer wins and pays off the second highest debt. The difference between cash and debt auctions is that cash bids are paid in advance, while debt is paid after output has been observed. This makes a difference only in the event of bankruptcy; however, bankruptcy cannot occur because the output always exceeds the requested debt payment. ${ }^{9}$. In order to show this, let $d^{\prime}$ denote the second highest IOU; then, the winner's profit is $x_{i}+e_{H}-d^{\prime}>x_{i}+e_{H}-d_{i}=c_{H}>0$, as asserted.

Proposition 2 (Call option). In equilibrium the winner plays the effort strategy $e_{i}\left(k^{\prime}\right)$, as a function of the second lowest strike price $k^{\prime}$, with $e_{i}\left(k^{\prime}\right)=e_{H}$ if $k^{\prime}>x+e_{L}+\Delta c$ and $e_{i}\left(k^{\prime}\right)=e_{L}$ otherwise. Each bidder bids the strike price $k_{i}=c_{L}$. On the equilibrium path the winner is chosen at random among all bidders and then chooses low effort. The principal's expected revenue is equal to

$$
\Pi^{k}=E(X)+e_{L}-c_{L}
$$

Proof. The principal will exercise his call option if and only if the strike price he has to pay, $k^{\prime}$, is less than the observed output of the winner, $x+e_{i}$. Taking this into account, in the effort subgame the winner chooses $e_{H}$ if and only if

$$
\min \left\{x+e_{H}, k^{\prime}\right\}-c_{H}>\min \left\{x+e_{L}, k^{\prime}\right\}-c_{L} .
$$

By checking all possible cases ${ }^{10}$ one finds that this is true if and only if $k^{\prime}>x+e_{L}+\Delta c$.

Given the equilibrium effort strategy, it is, again, a weakly dominant strategy to bid a strike price equal to $c_{L}$. And on the equilibrium path, the winner chooses $e_{L}$.

Because in equilibrium all bids are the same, the principal selects the winner at random and exercises the option. Therefore, his expected payoff is as asserted.

We mention that the call option can be interpreted as a standard fixed-wage contract, where the winning bidder is paid a fixed wage equal to $k$. This is due to the fact that in equilibrium the option is exercised with probability one, and bankruptcy never occurs. Not surprisingly, a fixed-wage contract lacks effort incentives, which is why the winner exerts low effort, $e=e_{L}$.

\footnotetext{
${ }^{9}$ See, however, the extension of our model to include uncertainty and limited liability in Section 9

${ }^{10}$ Altogether, there are three cases: 1) $k^{\prime}>x+e_{H}$, 2) $k^{\prime} \in\left(x+e_{L}, x+e_{H}\right)$, 3) $k^{\prime}<x+e_{L}$. In each case, the stated condition must hold.
} 
Lemma 1 (Share auction). 1) The winner's equilibrium effort strategy is a function of the second highest share, $s^{\prime}$ :

$$
e\left(s^{\prime}\right)= \begin{cases}e_{H} & \text { if } \quad s^{\prime} \leq s_{0}:=\frac{\Delta e-\Delta c}{\Delta e} \\ e_{L} & \text { otherwise }\end{cases}
$$

2) Conditional on choosing effort $e_{i}$, the equilibrium share function is

$$
s_{i}(x)=1-\frac{c_{i}}{x+e_{i}}, \quad i \in\{L, H\} .
$$

Proof. 1) Given $s^{\prime}$, the winner chooses high effort if and only $\left(1-s^{\prime}\right)\left(x+e_{H}\right)-c_{H}>\left(1-s^{\prime}\right)(x+$ $\left.e_{L}\right)-c_{L}$.

2) The equilibrium bid must be such that the bidder never regrets losing, independent of the rivals' bids, i.e., $\left(1-s_{i}(x)\right)\left(x_{i}+e_{i}\right)=c_{i}$.

Lemma 2 (Share auction). The functions $s_{H}, s_{L}$ are single-crossing:

$$
s_{H}(x) \gtreqless s_{L}(x) \Longleftrightarrow s_{H}(x) \lesseqgtr s_{0} .
$$

At the crossing point $x_{0}$ :

$$
x_{0}:=\frac{c_{L} \Delta e-e_{L} \Delta c}{\Delta c}
$$

one has $s_{H}\left(x_{0}\right)=s_{L}\left(x_{0}\right)=s_{0}$, provided $x_{0} \in[0,1]$.

The proof follows immediately from Lemma 1.

Proposition 3 (Share auction). In equilibrium each bidder plays the bid strategy:

$$
s(x)=\max \left\{s_{L}(x), s_{H}(x)\right\},
$$

and the effort strategy (4). As $s(x)$ is increasing in $x$, the highest type is selected as a winner. The principal's expected revenue is equal to

$$
\Pi^{s}=\int_{0}^{1} \int_{0}^{x} s(y)(x+e(s(y))) f_{(12)}(x, y) d y d x .
$$

Proof. Consider a bidder with $x>x_{0}$. Suppose that bidder deviates from the candidate equilibrium strategy and bids a share $s>s_{L}(x)$. If that makes a difference, the bidder wins with the deviating bid, $s$, but would have lost if he had bid $s_{L}(x)$. In that event, he must pay a share that is at least as high as $s_{L}(x)$. Because by definition of $s_{L}$ his profit is non-positive if he pays $s_{L}$ (no matter which effort he then chooses), this deviation is not profitable. The argument for the case when $s<s_{L}(x)$ is similar. The same applies to the case $x<x_{0}$.

The equilibrium of the share auction is illustrated in Figure 1 for the case $x_{0} \in(0,1) .{ }^{11}$ The equilibrium bid function is the upper envelope $s(x):=\max \left\{s_{L}(x), s_{H}(x)\right\}$, and, depending upon the second highest share, $s^{\prime}$, the winner chooses $e\left(s^{\prime}\right)=e_{H}$ for all $s^{\prime}<s_{0}$ and $e\left(s^{\prime}\right)=e_{L}$ for all $s^{\prime}>s_{0} \cdot{ }^{12}$

\footnotetext{
${ }^{11}$ This plot assumes uniformly distributed abilities and $\left(e_{H}, e_{L}, c_{H}, c_{L}\right)=(3.3,2,1.5,1)$.

${ }^{12}$ When the returns to additional effort $(\Delta e / \Delta c)$ is high, $s_{0}$ is close to 1 so that $e_{H}$ is more likely to be chosen by the winner. Thus share auction tends to yield more revenue than the cash auction when $\Delta e / \Delta c$ is high. A similar result is obtained in Kogan and Morgan (2010) who analyze venture capital financing through either debt or equity auctions.
} 


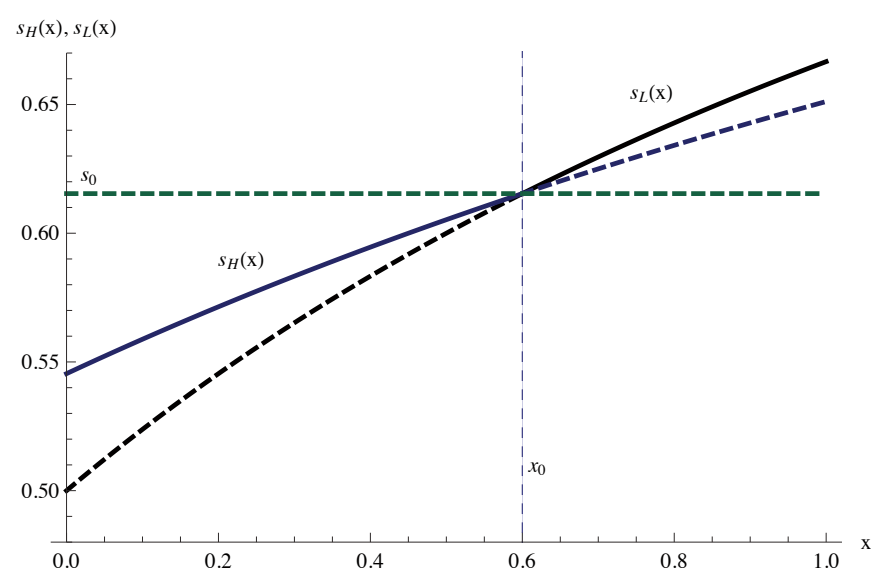

Figure 1: Share auction: (upper envelope) equilibrium bid function for $x_{0} \in(0,1)$

On the equilibrium path, the share auction yields a high output share (high extraction) combined with low effort if the two highest productivity parameters, $x>x^{\prime}$, are both higher than $x_{0}$, and it yields low extraction combined with high effort if $x^{\prime}<x_{0}$. This is in sharp contrast to the cash/debt and the call auction where we have either full incentives combined with low extraction (cash/debt auction) or low incentives combined with full extraction (call auction).

Of course, if $n$ is very large, the share auction is dominated by the cash auction because then the second order statistic approaches the first order statistic and the cash auction tends to extract the full surplus because it induces high effort. However, the following generalized share auction tends to be more profitable than the cash auction for all $n$, as we show below.

\section{Generalized share auction}

In his comment to Hansen (1985), who had introduced share auctions to the literature, Crémer (1987) claimed that the auctioneer can extract almost the full surplus by adding a positive cash reward to the winner. Following this suggestion, we now add a lump-sum transfer, $r$, to be paid in cash to the winner of the share auction. This reward may be either positive or negative. We will show that the performance of the share auction can thereby be improved, although full surplus extraction cannot be achieved, unless one is satisfied with implementing low effort.

The cash reward can be regarded as reducing the cost of the winner from $c$ to $c-r$. Therefore, by (5), equilibrium share functions $s_{L}, s_{H}$ are increasing while the threshold level $x_{0}$ is decreasing in $r:$

$$
s_{i}(x ; r)=1-\frac{c_{i}-r}{x+e_{i}}, i \in\{L, H\}, \quad x_{0}(r)=\frac{\left(c_{L}-r\right) \Delta e-e_{L} \Delta c}{\Delta c} .
$$

It follows that adding a positive reward increases the share of the auctioneer, which contributes to increase his revenue, yet may adversely affect effort incentives; whereas, adding a negative reward reduces his profit share, yet may strengthen effort incentives. The optimal generalized share auction balances this trade-off between surplus extraction and effort incentives.

We denote the expected revenue of the principal in the generalized share auction by $\Pi^{s}(r)$, and the maximizer of $\Pi^{s}(r)$ by $r^{*}$.

Proposition 4 (Generalized Share Auction). The generalized share auction: 1) can implement low effort and full surplus extraction, but 2) cannot implement high effort and full surplus extraction. 
3) The optimal generalized share auction exhibits an effort "distortion at the top", i.e., it exhibits $x_{0}\left(r^{*}\right)<1$.

Proof. Let $x, x^{\prime}$ denote the highest and second highest productivity parameters.

1) To prove this, let $r \rightarrow c_{L}$. This implies $x_{0}<0$, by (10), hence $s(x)=s_{L}(x)$ for all $x$ and the winner chooses $e_{L}$, and the share paid by the winner approaches 1 , by (10). Therefore, one can implement low effort and full surplus extraction.

2) Assume the mechanism implements $e_{H}$. Then, the principal's expected revenue is

$$
\begin{aligned}
\pi & =s_{H}\left(x^{\prime}\right)\left(x+e_{H}\right)-r \\
& =s_{H}(x)\left(x+e_{H}\right)-r-\left(s_{H}(x)-s_{H}\left(x^{\prime}\right)\right)\left(x+e_{H}\right) \\
& =x+e_{H}-\left(c_{H}-r\right)-r-\left(s_{H}(x)-s_{H}\left(x^{\prime}\right)\right)\left(x+e_{H}\right) .
\end{aligned}
$$

According to the equilibrium bidding strategies of the highest and the second highest bidders,

$$
\left(1-s_{H}\left(x^{\prime}\right)\right)\left(x^{\prime}+e_{H}\right)-c_{H}=\left(1-s_{H}(x)\right)\left(x+e_{H}\right)-c_{H}=0 .
$$

Rearranging (12) gives,

$$
\left(s_{H}(x)-s_{H}\left(x^{\prime}\right)\right)\left(x+e_{H}\right)=\left(1-s_{H}\left(x^{\prime}\right)\right)\left(x-x^{\prime}\right) .
$$

Combining (11) and (13), we get

$$
x+e_{H}-c_{H}-\pi=\left(1-s_{H}\left(x^{\prime}\right)\right)\left(x-x^{\prime}\right) \geq\left(1-s_{0}\right)\left(x-x^{\prime}\right) .
$$

Hence,

$$
\pi \leq x+e_{H}-c_{H}-\left(1-s_{0}\right)\left(x-x^{\prime}\right)<x+e_{H}-c_{H} .
$$

Therefore, the principal's expected revenue is bounded away from the expected surplus.

3) Suppose, per absurdum, that the profit maximizer of $\Pi^{s}(r)$, denoted by $r^{*}$, is such that $x_{0}\left(r^{*}\right) \geq$ 1. Then, by slightly increasing the cash reward, $d r>0$, in such a way that $e_{H}$ remains optimal for all $x$ (i.e., $x_{0}\left(r^{*}+d r\right)>1$ ), the principal's expected revenue can be increased for the following reason. Denote the increment in the second highest share that is induced by $d r$ by $d s^{\prime}$. In the equilibrium of the Vickrey auction $\left(x^{\prime}+e_{H}\right)\left(1-s^{\prime}\right)-c_{H}+r \equiv 0$. Therefore, $\left(x^{\prime}+e_{H}\right) d s^{\prime}-d r \equiv 0$, which implies that by increasing $r$ the principal's revenue increases by the amount:

$$
\left(x+e_{H}\right) d s^{\prime}-d r>\left(x^{\prime}+e_{H}\right) d s^{\prime}-d r \equiv 0 .
$$

Finally, denote the $r$ that induces $x_{0}(r)=1$ by $\bar{r}$. Evidently,

$$
\left.\partial_{r} \Pi^{s}(r)\right|_{r=\bar{r}}=\int_{0}^{1} \int_{0}^{x}\left(\frac{x+e_{H}}{y+e_{H}}-1\right) f_{(12)}(x, y) d y d x>0 .
$$

This is a contradiction. Therefore, the optimal cash reward $r^{*}$ is greater than $\bar{r}$, and $r^{*}$ induces $x_{0}\left(r^{*}\right)<1$, as asserted.

Note that the generalized share auction dominates the call-option in which the agent is selected at random who then exerts low effort. This is the reverse of the ranking in DeMarzo et al. (2005) where the call option auction is the revenue maximizing security bid auction. 


\section{5 "Hybrid cash" and "hybrid share auctions"}

Generally, one can improve the profitability of the cash auction by adding a minimum price requirement. ${ }^{13}$ In the present framework, the optimal cash auction is a modified Vickrey auction with a minimum price $t=t^{*}$ that is implicitly defined as the unique solution of the equation ${ }^{14}$

$$
t^{*}=\frac{1-F\left(t^{*}-\left(e_{H}-c_{H}\right)\right)}{F^{\prime}\left(t^{*}-\left(e_{H}-c_{H}\right)\right)} .
$$

However, its profitability can be further increased by a "hybrid cash auction" that includes an option to become residual claimant and pay a fixed wage.

A "hybrid cash" auction is a cash auction that is supplemented in two ways: 1) the price rule is supplemented by a reserve price $t$, and 2) the principal is given an option to draw one agent at random, employ him, and pay him a fixed wage equal to $c_{L}$ in the event when no bidder met the reserve.

Obviously, the second modification of the cash auction increases the profitability of a cash auction that is subject to a reserve price because it replaces the "no trade" that occurs if no bidder meets the reserve by a profitable wage contract.

Specifically, setting a positive reserve price $t$ induces a cutoff strategy according to which bidders submit a bid if and only if their type is greater or equal to $\tau=t-\left(e_{H}-c_{H}\right)$. In the event when all agents' types are below $\tau$, which occurs with probability $F(\tau)^{n}$, no agent bids. In that case, the option can and will be exercised, and the principal earns a positive expected profit equal to $E[X \mid X \leq \tau]+e_{L}-c_{L}$.

The "optimal hybrid cash auction" sets that reserve price $t$ that maximizes the principal's expected profit. The optimal reserve price is higher than that of the optimal cash auction, $t^{*}$, because if one replaces "no trade" by a profitable wage contract, the reserve price extracts more surplus at lower marginal cost.

Similarly, one can improve the profitability of the generalized share auction by including a minimum share requirement together with the provision that the principal can draw one agent at random, employ him, and pay a minimum wage equal to $c_{L}$ in the event when no agent submitted a bid. This begs the question whether the considered auction formats can be ranked by their profitability for the seller, which we answer in Section 6.

\section{Performance ranking}

To prepare the ranking of the above mechanisms, we introduce the following conditions:

$$
\begin{gathered}
\frac{e_{H}}{\left(e_{H}+1\right)}>\frac{\Delta c}{\Delta e} \\
\Delta e-\Delta c>E(X)-E\left(X_{(2: n)}\right) .
\end{gathered}
$$

Condition $\mathrm{A}$ is slightly stronger than our assumption concerning the technology. Whereas our assumption requires $\Delta c / \Delta e<1$, condition $\mathrm{A}$ requires that $\Delta c / \Delta e$ is smaller than the ratio $e_{H} /\left(e_{H}+1\right)$

\footnotetext{
${ }^{13}$ Of course, depending upon the parameters, the optimal minimum price may never be binding; in that case, the cash auction without minimum price is already optimal. For example, if $F$ is the uniform distribution with support $[0,1]$, the minimum price never binds if and only if $e_{H}-c_{H} \geq 1$.

${ }^{14}$ Proof: Define the random variable $V:=X+e_{H}-c_{H}$, compute the c.d.f. of $V$, and then apply the optimal reserve price rule for the symmetric optimal auction problem in Myerson (1981) for the case when the seller's reservation value is equal to zero. Since $F$ exhibits an increasing hazard rate then rule (14) has a unique solution.
} 
which is itself smaller than one. Therefore, condition A is satisfied if the technology is sufficiently productive.

Condition $\mathrm{B}$ is a weak requirement concerning the number of bidders and their productivity. It can only be violated if $E(X)>E\left(X_{(2: n)}\right)$; if $F$ is the uniform distribution, this is possible if and only if $n=2$.

Proposition 5 (Ranking I). The generalized share auction is more profitable than the cash/debt auction if condition A holds, and the cash auction is more profitable than the call auction if condition $B$ holds.

Proof. 1) We will show that by choosing a reward $r \leq c_{L}$ (either positive or negative) in such a way that $x_{0}(r)=1$, the principal can induce bidders to choose high effort for all type profiles, and earn a higher expected revenue than in the cash auction. Therefore, in the optimal generalized share auction the principal's expected revenue must be higher than that of the cash auction.

From (10) it follows that one can induce $x_{0}=1$ by offering the reward

$$
r_{1}:=c_{H}-\frac{\Delta c}{\Delta e}\left(1+e_{H}\right) .
$$

If this is done, high effort is chosen by all types. Let $x, x^{\prime}$ be the highest and second highest productivity parameters. Then, the associated revenue of the principal can be assessed as follows:

$$
\begin{aligned}
s_{H}\left(x^{\prime}\right)\left(x+e_{H}\right)-r_{1} & =\left(1-\frac{c_{H}-r_{1}}{x^{\prime}+e_{H}}\right)\left(x+e_{H}\right)-r_{1} \\
& =\left(x^{\prime}+e_{H}-c_{H}+r_{1}\right) \frac{x+e_{H}}{x^{\prime}+e_{H}}-r_{1} \\
& \left.>\left(x^{\prime}+e_{H}-c_{H}+r_{1}\right)-r_{1} \quad \text { (because } A \Rightarrow e_{H}-c_{H}+r_{1}>0\right) \\
& =x^{\prime}+e_{H}-c_{H} \quad \text { (revenue in cash auction). }
\end{aligned}
$$

There, the inequality follows from the fact that $\left(x+e_{H}\right) /\left(x^{\prime}+e_{H}\right)>1$ and $e_{H}-c_{H}+r_{1}>0$, which are implied by the assumption of the proposition.

2) By (2) and (3) one finds that $\Pi^{c}>\Pi^{k}$ if and only if condition B holds.

We finally come to our main results:

Proposition 6 (Ranking II). The optimal hybrid share auction is more profitable than the optimal hybrid cash auction if condition A holds.

Proof. Suppose the optimal hybrid cash auction prescribes the reserve price $t$ that induces the cutoff value $\tau$. Consider the generalized share auction with the cash reward $r_{1}$, that induces $x_{0}=1$, and the minimum share $\underline{s}$ :

$$
\underline{s}:=1-\frac{c_{H}-r_{1}}{\tau+e_{H}} .
$$

Then, the expected payoff of a bidder with ability $x$ who makes a bid is

$$
\int_{0}^{x}\left((1-\max \{\underline{s}, \bar{s}(y)\})\left(x+e_{H}\right)-c_{H}\right) f_{(1: n-1)}(y) d y \gtreqless 0 \Longleftrightarrow x \gtreqless \tau .
$$

Therefore, that minimum share induces the same participation strategy as the optimal hybrid cash auction. 
By definition of $r_{1}$, the assumed cash reward induces $e_{H}$ and the share bid $\bar{s}(x):=s_{H}\left(x ; r_{1}\right)=$ $1-\frac{c_{H}-r_{1}}{x+e_{H}}$, by (10) for all $x \geq \tau$. Therefore, if $X_{(1)} \geq \tau$, the random profit of the principal is equal to

$$
\left\{\begin{array}{l}
\bar{s}\left(X_{(2)}\right)\left(X_{(1)}+e_{H}\right)-r_{1}=X_{(2)}+e_{H}-c_{H}+\bar{s}\left(X_{(2)}\right)\left(X_{(1)}-X_{(2)}\right), \quad \text { if } X_{(2)} \geq \tau \\
\underline{s}\left(X_{(1)}+e_{H}\right)-r_{1}=\tau+e_{H}-c_{H}+\underline{s}\left(X_{(1)}-\tau\right), \quad \text { if } X_{(2)}<\tau .
\end{array}\right.
$$

Because, using the definition of $r_{1}$ (see equation (15)):

$$
\text { condition } \mathrm{A} \Rightarrow \underline{s}=1-\frac{c_{H}-r_{1}}{\tau+e_{H}}=1-\frac{\Delta c}{\Delta e} \frac{\left(1+e_{H}\right)}{\left(\tau+e_{H}\right)} \geq 1-\frac{\Delta c}{\Delta e} \frac{\left(1+e_{H}\right)}{e_{H}}>0,
$$

and the fact that $\bar{s}(\cdot)$ is monotone increasing, it follows that $\bar{s}\left(X_{(2)}\right) \geq \underline{s}>0$. Therefore, in both cases the random profit is greater than under the corresponding optimal hybrid cash auction, which is

$$
\begin{cases}X_{(2)}+e_{H}-c_{H} & \text { if } \quad X_{(2)} \geq \tau \\ \tau+e_{H}-c_{H} & \text { if } \quad X_{(2)}<\tau\end{cases}
$$

And if $X_{(1)}<\tau$, the random profit of the principal is evidently the same as in the optimal hybrid cash auction.

We have thus constructed a hybrid share auction that is more profitable than the optimal hybrid cash auction. Evidently, the optimal hybrid share auction that sets the optimal minimum share is even more profitable.

Corollary 1. If condition A holds the optimal hybrid share auction is more profitable than all other auction formats.

\section{Comparison with the optimal mechanism}

In order to compare the performance of the above security bid auctions with that of the optimal mechanism we now characterize the optimal mechanism. ${ }^{15}$

By the revelation principle, one can restrict attention to direct mechanisms $(T, Q, \psi)$ that are truthfully implementable in Bayesian Nash equilibrium and assure voluntary participation. There, $T_{i}:[0,1]^{n} \rightarrow \mathbb{R}$ is the transfer to player $i$, and $Q_{i}:[0,1]^{n} \rightarrow[0,1]$ his probability of winning, as functions of the reported type profile. In addition, the mechanism prescribes the output that the winner is required to deliver as a function of the winner's reported type, $\psi:[0,1] \rightarrow \mathbb{R} .^{16}$

The optimal mechanism, which is derived in detail in the Appendix, is summarized as follows:

\footnotetext{
${ }^{15}$ In their model of optimal regulation of a monopoly, Laffont and Tirole (1987) assume a similar additive structure to characterizes an optimal mechanism. Their solution is, however, not applicable in the present framework. See also McAfee and McMillan (1987).

${ }^{16}$ Failure to deliver the prescribed output triggers a sufficiently high penalty.
} 
Proposition 7 (Optimal Mechanism). The optimal mechanism $(\psi, Q, T)$, prescribes the following output target, $\psi$, allocation rules $Q_{i}$, and transfer rule $T_{i}$, for all agents $i$ :

$$
\begin{aligned}
\psi(x) & = \begin{cases}x+e_{L} & \text { if } \quad x<\hat{x} \\
x+e_{H} & \text { otherwise }\end{cases} \\
Q_{i}\left(x_{i}, x_{-i}\right) & =\left\{\begin{array}{lll}
1 & \text { if } & x_{i} \geq \max \left\{x_{-i}\right\} \\
0 & \text { if } & x_{i}<\max \left\{x_{-i}\right\},
\end{array}\right. \\
T_{i}\left(x_{i}, x_{-i}\right) & = \begin{cases}Q_{i}\left(x_{i}, x_{-i}\right) c_{L} & \text { if } x_{i}<\hat{x} \\
Q_{i}\left(x_{i}, x_{-i}\right) c_{H}+u\left(x_{i}\right) & \text { otherwise }\end{cases} \\
u(x) & = \begin{cases}0 & \text { for } x<\hat{x}+\Delta e \\
\sum_{j=1}^{k-1} G(x-j \Delta e) \Delta c & \text { for } x \in[\hat{x}+(k-1) \Delta e, \hat{x}+k \Delta e) \\
& \text { and } k \in\{2, \ldots, \bar{k}\}\end{cases}
\end{aligned}
$$

where $\bar{k}$ is defined as the smallest integer $k$ for which $\hat{x}+k \Delta e>1$ and $\hat{x}:=\inf \left\{x \mid x \in X_{H}\right\}$, and $X_{H}:=\left\{x \mid \psi(x)=x+e_{H}\right\}$.

It exhibits "no distortion at the top" and generally a "distortion at the bottom", i.e., it implements low effort only if the winner's ability is sufficiently low. ${ }^{17}$

Corollary 2. None of the considered auction formats is optimal.

Proof. The optimal mechanism exhibit "no distortion at the top" and generally a distortion at the bottom. Whereas the optimal generalized share auction exhibits an "effort distortion at the top" because it implies that the winner chooses low effort if the second highest productivity parameter is below $x_{0}\left(r^{*}\right)$, where $x_{0}\left(r^{*}\right)<1$ by Proposition 4. Therefore, the optimal generalized share auction is not an optimal mechanism. Among all considered auctions only the optimal hybrid cash auction exhibits the same pattern of distortions as the optimal mechanism. However, it is less profitable than the optimal hybrid share auction; therefore, it is not optimal either.

To illustrate the performance ranking, we compute the expected profits for each of the above auction formats and for the optimal mechanism.

Example 1. Suppose $n=2, F(x)=x,\left(e_{H}, e_{L}, c_{H}, c_{L}\right)=(4 / 5,2 / 5,1 / 2,3 / 10)$. Then, the different mechanisms yield the expected profits of the principal that are summarized in Table 1. There, "plain" refers to auctions without reserve price, "optimal cash" refers to the cash auction with optimal reserve, and "hybrid auctions" are optimal hybrid auctions. ${ }^{18}$

\section{A generalized hybrid share auction that (arbitrary closely) implements the opti- mal mechanism}

One may wonder why there is a discrepancy between the most profitable security bid auction and the optimal mechanism. The reason is that the optimal mechanism makes use of output requirements as a function of the reported ability, which is not an ingredient of security bid auctions. This suggests that by adding output targets to hybrid share auctions one may increase their profitability.

\footnotetext{
${ }^{17}$ The distortion at the bottom does not occur if the technology is highly productive. A distortion at the bottom occurs, for example, if $F$ is the uniform distribution, $\Delta e / \Delta c<3 / 2, \Delta e<1 / 2$, and $n=2$.

${ }^{18}$ Note, the numerical example does not satisfy condition A, which indicates that condition A is sufficient but not necessary for the asserted ranking.
} 


\begin{tabular}{c|ccc|ccc|c}
\hline Call & \multicolumn{3}{|c|}{ Cash Auctions } & \multicolumn{3}{c|}{ Share Auctions } & Optimal \\
Auction & Plain & Optimal & Hybrid & Plain & Generalized & Hybrid & Mechanism \\
\hline 0.6000 & 0.6333 & 0.6619 & 0.7426 & 0.6810 & 0.7058 & 0.7888 & 0.8947 \\
\hline
\end{tabular}

Table 1: Principal's Expected Profit

We design a generalized hybrid share auction that includes output targets and (arbitrary closely) implements the optimal mechanism.

We proceed as follows: first we design a truthfully implementable direct mechanism that arbitrary closely replicates the optimal mechanism, and then show that it is implementable by a hybrid share auction.

In the direct mechanism agents report their ability and the principal awards the incentive contract to the agent who reported the highest type. The mechanism prescribes a transfer from the principal to the winner as a function of the winner's reported ability $x$ and the second highest reported ability $x^{\prime}$

$$
\begin{aligned}
\tilde{t}\left(x, x^{\prime}\right) & =\left(1-\tilde{s}\left(x^{\prime}\right)\right) \phi\left(x, e_{i}\right)+\tilde{r}(x) \\
\tilde{s}\left(x^{\prime}\right) & = \begin{cases}1-\frac{\varepsilon}{x^{\prime}+e_{L}} & \text { if } x^{\prime}<\hat{x} \\
1-\frac{\varepsilon}{x^{\prime}+e_{H}} & \text { if } x^{\prime} \geq \hat{x} .\end{cases}
\end{aligned}
$$

There 1) $\phi\left(x, e_{i}\right)$ is the output based on the agent's choice of effort $e_{i}$, which must be greater or equal to the output target $\psi(x)$ (defined in (16)), 2) $\varepsilon>0$, and 3) $\tilde{r}(x)$ is a cash reward as a function of the reported ability, defined as:

$$
\begin{aligned}
\tilde{r}(x) & =\frac{u(x)}{G(x)}+r_{0}(x) \\
r_{0}(x) & := \begin{cases}c_{L}-\varepsilon & \text { for } x<\hat{x} \\
c_{H}-\varepsilon & \text { for } x \geq \hat{x} .\end{cases}
\end{aligned}
$$

where $\bar{k}$ is defined as the smallest integer $k$ for which $\hat{x}+k \Delta e>1$ and $u(x)$ is defined in (19).

Proposition 8. The above direct mechanism 1) induces truthtelling, 2) induces the same effort choice as the optimal mechanism, 3) by choosing $\varepsilon$ arbitrarily small yields (approximately) the same expected profit of the principal as the optimal mechanism; 4) can be implemented by a hybrid share auction that includes a prescription of output targets.

Proof. 1a) Suppose the agent's true ability is $x<\hat{x}$.

If he reports ability $z$, he is obliged to deliver an output of at least $\psi(z)$. If he overstates his ability, i.e., $z>x$, he cannot go beyond $z=\min \{x+\Delta e, \hat{x}\}$, because if he reports $z>\hat{x}$ he has to deliver at least $z+e_{H}$, which he cannot; similarly, if he reports $z>x+\Delta e$ he has to deliver at least $z+e_{L}$, which exceeds $x+e_{H}$, which he cannot either. Of course, if the agent understates his ability, he can always fulfill the output target.

Suppose the agent overstates his ability, $\min \{x+\Delta e, \hat{x}\} \geq z>x$. This can only make a difference if the second highest reported ability, $x^{\prime}$, is in between $x$ and $z$. In this case the agent's payoff can 
be assessed as follows (where the first equation follows from (22), (23))

$$
\begin{aligned}
&\left(1-\tilde{s}\left(x^{\prime}\right)\right)\left(x+e_{H}\right)+\tilde{r}(x)-c_{H} \\
&=\left(1-\tilde{s}\left(x^{\prime}\right)\right)\left(x^{\prime}+e_{L}+\Delta e+x-x^{\prime}\right)-\varepsilon-\Delta c \\
&=\left(1-\tilde{s}\left(x^{\prime}\right)\right)\left(x^{\prime}+e_{L}\right)-\varepsilon+\left(1-\tilde{s}\left(x^{\prime}\right)\right)\left(\Delta e+x-x^{\prime}\right)-\Delta c \\
&=\frac{\varepsilon}{x^{\prime}+e_{L}}\left(\Delta e+x-x^{\prime}\right)-\Delta c \text { by definition of } \tilde{s}\left(x^{\prime}\right) \text { for } x^{\prime}<\hat{x} \\
&<0 \quad \text { because } \varepsilon \text { is arbitrarily close to } 0 .
\end{aligned}
$$

Therefore, overstating does not pay.

Suppose the agent understates his ability, $z<x$ (in which case he can fulfill his output target). Understating makes a difference only if the second highest reported ability, $x^{\prime}$, is in between $x$ and $z$. In this case the agent turns from a winner to a loser and forgoes a profit.

1b) Suppose the agent's true ability is $x \geq \hat{x}$. Then $x \in[\hat{x}+(k-1) \Delta e, \hat{x}+k \Delta e)$, for some integer $k$.

If he reports ability $z$, he is obliged to deliver an output of at least $\psi(z)$. If he overstates his ability, i.e., $z>x$, he has to deliver an output that is greater or equal to $\psi(z)$ which exceeds $x+e_{H}$, and hence is not feasible.

Therefore we only need to consider that the agent understates his ability, $z<x$, in which case he can always fulfill the output target. We distinguish two cases.

1b-1) Suppose $x \in[\hat{x}, \hat{x}+\Delta e)$. If the agent reports $z \geq \hat{x}$ and wins, he cannot reduce his effort (without violating the output target), and he can neither change his cash reward nor his share. However, he lowers the chance of winning. Therefore, this kind of understating is not profitable.

Whereas if the agents reports $z<\hat{x}$ and wins, he can reduce his effort to $e_{L}$. This reduces his cost by $\Delta c$, yet, at the same time reduces his cash reward by $\Delta c$. However, this lowers the chance of winning. Therefore, this kind of understating is not profitable either.

1b-2) Suppose $x \in[\hat{x}+(k-1) \Delta e, \hat{x}+k \Delta e)$ for $k \in\{2, \ldots, \bar{k}\}$. If $x>z>x-\Delta e$, the agent cannot reduce his effort, and his expected payoffs from truthtelling, $\tilde{U}_{x}$, and from reporting $z, \tilde{U}_{z}$, are:

$$
\begin{aligned}
\tilde{U}_{x} & =G(x)\left(\left(1-\tilde{s}\left(x^{\prime}\right)\right)\left(x+e_{H}\right)+\frac{u(x)}{G(x)}+c_{H}-\varepsilon-c_{H}\right) \\
\tilde{U}_{z} & =G(z)\left(\left(1-\tilde{s}\left(x^{\prime}\right)\right)\left(x+e_{H}\right)+\frac{u(z)}{G(z)}+c_{H}-\varepsilon-c_{H}\right) \\
\Rightarrow \quad \tilde{U}_{x}-\tilde{U}_{z} & =(G(x)-G(z))\left(\left(1-\tilde{s}\left(x^{\prime}\right)\right)\left(x+e_{H}\right)-\varepsilon\right)+u(x)-u(z) .
\end{aligned}
$$

The latter is positive because $u$ is non-decreasing, $G$ is increasing, and $\left(1-\tilde{s}\left(x^{\prime}\right)\right)\left(x+e_{H}\right)-\varepsilon>0$.

Whereas if $z \leq x-\Delta e$, the agent can reduce his effort to $e_{L}$, which yields

$$
\begin{aligned}
\tilde{U}_{x} & =G(x)\left(\left(1-\tilde{s}\left(x^{\prime}\right)\right)\left(x+e_{H}\right)+\frac{u(x)}{G(x)}+c_{H}-\varepsilon-c_{H}\right) \\
\tilde{U}_{z} & =G(z)\left(\left(1-\tilde{s}\left(x^{\prime}\right)\right)\left(x+e_{L}\right)+\frac{u(z)}{G(z)}+c_{H}-\varepsilon-c_{L}\right) \\
\Rightarrow \quad \tilde{U}_{x}-\tilde{U}_{z}> & (G(x)-G(z))\left(\left(1-\tilde{s}\left(x^{\prime}\right)\right)\left(x+e_{H}\right)-\varepsilon\right)+u(x)-u(z)-G(z) \Delta c .
\end{aligned}
$$


Note that, because $u$ and $G$ are monotone increasing:

$$
\begin{aligned}
u(z)+G(z) \Delta c & \leq u(x-\Delta e)+G(x-\Delta e) \Delta c \\
& =\sum_{j=1}^{k-2} G(x-\Delta e-j \Delta e) \Delta c+G(x-\Delta e) \Delta c \quad \text { by (19) } \\
& =\sum_{j=2}^{k-1} G(x-j \Delta e) \Delta c+G(x-\Delta e) \Delta c \\
& =u(x) .
\end{aligned}
$$

Therefore, $\tilde{U}_{x}-\tilde{U}_{z}>0$. We have thus shown that the mechanism induces truth-telling.

2) Suppose $x<\hat{x}$. Then, low effort is optimal for the winner because the difference between the payoffs from choosing high and low effort is

$$
\left(1-\tilde{s}\left(x^{\prime}\right)\right) \Delta e-\Delta c=\frac{\varepsilon}{x^{\prime}+e_{L}} \Delta e-\Delta c<0 \quad \text { because } \varepsilon \text { is arbitrarily close to } 0 .
$$

Suppose $x \geq \hat{x}$. Then the winner has to deliver the output $x+e_{H}$ which requires him to choose $e_{H}$.

3) Because truthtelling and the choice of the optimal effort level are assured, the principal's expected profits in the above mechanism, $\tilde{\Pi}$, and in the optimal mechanism, $\Pi^{*}$, are

$$
\begin{aligned}
\tilde{\Pi} & =n \int_{0}^{1}\left(G(x) \psi(x)-\int_{0}^{x} \tilde{t}\left(x, x^{\prime}\right) d G\left(x^{\prime}\right)\right) d F(x) \\
\Pi^{*} & =n \int_{0}^{1}(G(x) \psi(x)-t(x)) d F(x) .
\end{aligned}
$$

Using the definitions of $\tilde{t}$ and $t$ in (20), (A.4), and the fact that the output is in all cases equal to the output target, one finds: ${ }^{19}$

$$
\begin{aligned}
\Pi^{*}-\tilde{\Pi}= & n \int_{0}^{1}\left(\int_{0}^{x} \tilde{t}\left(x, x^{\prime}\right) d G\left(x^{\prime}\right)-t(x)\right) d F(x) \\
= & \varepsilon n \int_{0}^{\hat{x}}\left(\psi(x) \int_{0}^{x} \frac{1}{x^{\prime}+e_{L}} d G\left(x^{\prime}\right)-G(x)\right) d F(x) \\
& +\varepsilon n \int_{\hat{x}}^{1}\left(\psi(x) \int_{0}^{x} \frac{1}{x^{\prime}+e_{i}} d G\left(x^{\prime}\right)-G(x)\right) d F(x) .
\end{aligned}
$$

As $\varepsilon$ is made arbitrarily small, that difference becomes arbitrarily small.

4) This mechanism can be implemented by a second-price share auction. There, the principal announces an output target and a cash reward as a function of the highest bid, while agents compete in share (equity) bids. The function $\tilde{s}$ is the equilibrium bid function. The cash reward scheme is fine tuned to make the equilibrium share arbitrarily close to 1 .

\section{Extension: Adding uncertainty and limited liability}

One limitation of the above analysis is that it ignores uncertainty and limited liability. We now report some changes that occur if output is stochastic and agents lack independent financial resources and are subject to limited liability.

\footnotetext{
${ }^{19}$ In the following expressions, the $e_{i}$ term depends on $x^{\prime}$. However, we do not need to specify this dependency because these vanish as we let $\varepsilon$ go to zero, in any case.
} 
Without loss of generality we assume that output, $y$, as a function of ability and effort, is a binary random variable:

$$
\phi(x, e)= \begin{cases}x+e & \text { with probability } p \\ \alpha(x+e) & \text { with probability } 1-p\end{cases}
$$

where $\alpha, p \in(0,1)$. We also assume:

$$
\begin{gathered}
p \Delta e>\Delta c, \quad \bar{\alpha} e_{H}>c_{H} \\
\text { where } \quad \bar{\alpha}:=p+(1-p) \alpha .
\end{gathered}
$$

This assures that in cash and debt auctions agents have an incentive to choose high effort and that participation constraints are satisfied for all agents, independent of their ability.

By definition, in cash auctions bankruptcy is not an issue because cash auctions presume that bidders can pay in advance. Therefore, the equilibrium bid strategy in the cash auction under uncertainty, $b_{c}$, follows immediately from the usual break-even condition:

$$
b_{c}(x)=\bar{\alpha}\left(x+e_{H}\right)-c_{H} .
$$

The agent chooses high effort because, after he paid the second highest bid, he is a residual claimant and his expected gain of switching from low to high effort is equal to $\bar{\alpha} \Delta e-\Delta c$, which is positive by assumption (25).

Similarly, in share auctions bankruptcy is not an issue, and the equilibrium share follows from the corresponding break-even condition, which yields:

$$
s_{i}(x)=1-\frac{c_{i}}{\bar{\alpha}\left(x+e_{i}\right)}, \quad i \in\{L, H\}, \quad x_{0}=\frac{c_{L} \Delta e-e_{L} \Delta c}{\Delta c}, \quad s_{0}=1-\frac{\Delta c}{\bar{\alpha} \Delta e} .
$$

\subsection{Debt dominate cash auctions if bankruptcy is an issue}

Proposition 9. In the case of uncertainty and limited liability, the equilibrium bid strategy of the debt auction is:

$$
\begin{aligned}
b_{d}(x) & = \begin{cases}b_{c}(x) & \text { if } x \leq x_{d} \\
x+e_{H}-\frac{c_{H}}{p} & \text { if } x \geq x_{d}\end{cases} \\
x_{d}: & =\frac{c_{H}}{p(1-\alpha)}-e_{H},
\end{aligned}
$$

Bankruptcy occurs in the low output state only if the agent's ability is higher than $x_{d}$. At all levels of ability, the winner chooses high effort.

Proof. As usual, the equilibrium bid strategy must satisfy a break-even condition. Two possibilities must be distinguished: Either 1) the bidder can pay his bid in both low and high output states, or 2) he can pay his bid only in the high output state.

In case 1) the break-even condition is:

$$
p b_{d}(x)+(1-p) b_{d}(x)=\bar{\alpha}\left(x+e_{H}\right)-c_{H} ;
$$

in case 2) it is:

$$
p b_{d}(x)+(1-p) \alpha\left(x+e_{H}\right)=\bar{\alpha}\left(x+e_{H}\right)-c_{H} .
$$


Case 1) is possible if and only if $b_{d}(x) \leq \alpha\left(x+e_{H}\right)$, i.e., if and only if $x \leq x_{d}$; case 2) is possible if and only if $x \geq x_{d}$.

Like in cash auction the agent chooses high effort because his expected net gain of switching from low to high effort is greater or equal to $p \Delta e-\Delta c$ which is positive by assumption (25).

Note that $x_{d} \in(0,1)$ if and only if

$$
1-\frac{c_{H}}{p e_{H}}<\alpha<1-\frac{c_{H}}{p\left(1+e_{H}\right)}, \quad \text { and } \quad p>\frac{c_{H}}{\left(1+e_{H}\right)} .
$$

Obviously, if $x_{d} \geq 1$, the debt auction is equivalent to the cash auction.

We now show that the debt auction is more profitable for the seller than the cash auction. This may be surprising (for readers who are not familiar with security bid auctions) because the debt auction is subject to limited liability, whereas the cash auction assumes that bidder have the financial resources to pay in advance, which means that bankruptcy is not an issue. ${ }^{20}$

Proposition 10. Suppose $x_{d}<1$, then the debt auction is more profitable for the principal than the cash auction.

Proof. Let $\left(x, x^{\prime}\right)$ be the profile of the two highest ability levels, where $x>x^{\prime}$. Then, the principal's profits in debt and cash auctions, $\pi_{d}, \pi_{c}$, are ranked as follows:

$$
\begin{aligned}
\pi_{d} & =p b_{d}\left(x^{\prime}\right)+(1-p) \min \left\{b_{d}\left(x^{\prime}\right), \alpha\left(x+e_{H}\right)\right\} \\
& \geq p b_{d}\left(x^{\prime}\right)+(1-p) \min \left\{b_{d}\left(x^{\prime}\right), \alpha\left(x^{\prime}+e_{H}\right)\right\} \\
& =\bar{\alpha}\left(x^{\prime}+e_{H}\right)-c_{H} \quad \text { by }(31),(32) \\
& =b_{c}\left(x^{\prime}\right) \quad \text { by }(27) \\
& =\pi_{c} .
\end{aligned}
$$

The inequality is strict if and only if $x_{d}<x^{\prime}<x$. Therefore, the principal's expected revenue in the debt auction is higher than in the cash auction.

\subsection{Hybrid debt/share auctions dominate debt auctions}

However, the debt auction can always be improved by adding an equity component. In order to show this we design a hybrid debt/share mechanism that is more profitable for the principal than the debt auction. Again, we first design a direct mechanism that has the desired property, and then show that it can be implemented by a debt/share auction.

In the proposed direct mechanism agents report their abilities and the principal selects the agent who reported the highest type, $x$, as winner. The mechanism prescribes a transfer from the winner to the principal that is the same as the equilibrium transfer in the above debt auction if the second highest ability, $x^{\prime}$, is greater or equal to a threshold level that is stated below, and the same as the equilibrium transfer in the above share auction if $x^{\prime}$ is less than that threshold level.

While a debt auction has strong effort incentives, the share auction tends to distort the choice of effort. In our generalized share auction this problem was remedied by making agents pay some cash in advance. However, if agents are subject to uncertainty and limited liability and have no

\footnotetext{
${ }^{20}$ One may also consider the case when payments in the cash auction are postponed until output has been observed and must be paid out of the output. In that case the cash auction is of course equivalent to the debt auction.
} 
financial resources other than their revenue, this remedy is not available. Therefore, if one wants to design a superior hybrid debt/share mechanism under uncertainty and limited liability one must also make sure that efficient effort is induced.

In detail, the hybrid debt/share mechanism prescribes the following transfers, $t\left(x, x^{\prime}\right)$, from the winner to the principal, ${ }^{21}$ contingent on the observed output and the messages $x>x^{\prime}$ :

$$
t\left(x, x^{\prime}\right)= \begin{cases}s_{H}\left(x^{\prime}\right) \phi\left(x, e_{H}\right) & \text { if } x^{\prime}<\min \left\{x_{0}, x_{d}\right\} \\ \min \left\{b_{d}\left(x^{\prime}\right), \phi\left(x, e_{H}\right)\right\} & \text { if } x^{\prime} \geq \min \left\{x_{0}, x_{d}\right\}\end{cases}
$$

where $s_{H}, x_{0}, b_{d}$ are as defined in (28) and (29). The transfer that is prescribed if $x^{\prime}<\min \left\{x_{0}, x_{d}\right\}$ is simply the equilibrium bid in the share auction, and the transfer for $x^{\prime} \geq \min \left\{x_{0}, x_{d}\right\}$ is the same as in the above debt auction.

Proposition 11 (Hybrid debt/share mechanism). The hybrid debt/share mechanism 1) assures truth-telling, 2) induces the choice of high effort, 3) involves transfers that never exceed the output, 4) yields a higher expected profit for the principal than the debt auction, and 5) can be implemented by a hybrid debt/share auction in which agents submit either a debt or a share bid, subject to some constraints.

Proof. 1) Suppose $e=e_{H}$ (which will be confirmed later). If the agent with ability $x$ overstates his ability and reports $z>x$, this can only make a difference if $x<x^{\prime}<z$. Suppose $x^{\prime}<\min \left\{x_{0}, x_{d}\right\}$. Then the agent is awarded a share contract with share $s_{H}\left(x^{\prime}\right)$. At this share, the agent with ability $x^{\prime}$ would just break even if he were selected as winner. However, because $x<x^{\prime}$, the agent who overstated will suffer a loss. Similarly, if $x^{\prime} \geq \min \left\{x_{0}, x_{d}\right\}$, the agent is awarded the debt contract with debt $b_{d}\left(x^{\prime}\right)$. At this debt, the agent with ability $x^{\prime}$ would just break even if he were selected as winner. However, because $x<x^{\prime}$, the agent who overstated will suffer a loss. By similar reasoning agents cannot benefit from understating their ability either. Therefore, truthtelling is assured.

2) Suppose $x^{\prime}<\min \left\{x_{0}, x_{d}\right\}$. Then, the winner's expected payoff is maximized by choosing $e_{H}$, because

$$
\begin{aligned}
\left(1-s_{H}\left(x^{\prime}\right)\right) \bar{\alpha}\left(x+e_{H}\right) & -c_{H}-\left(\left(1-s_{H}\left(x^{\prime}\right)\right) \bar{\alpha}\left(x+e_{L}\right)-c_{L}\right) \\
& =\left(1-s_{H}\left(x^{\prime}\right)\right) \bar{\alpha} \Delta e-\Delta c \\
& >\left(1-s_{H}\left(x_{0}\right)\right) \bar{\alpha} \Delta e-\Delta c \\
& =0 \quad \text { by }(28) .
\end{aligned}
$$

If $x^{\prime} \geq \min \left\{x_{0}, x_{d}\right\}$, the winner's payoff is the same as in the debt auction in which high effort is optimal.

3) Because $s_{H}\left(x^{\prime}\right)<1$, the winner's transfer is less than his output in both states for all $x^{\prime}<$ $\min \left\{x_{0}, x_{d}\right\}$. Of course, in the debt contract, the winner's transfer never exceeds his output.

4) Suppose $x^{\prime}<\min \left\{x_{0}, x_{d}\right\}$. Then, the principal's expected profit is greater than in the debt auction (where bankruptcy cannot occur for those levels of ability) because:

$$
\begin{aligned}
s_{H}\left(x^{\prime}\right) \bar{\alpha}\left(x+e_{H}\right) & >s_{H}\left(x^{\prime}\right) \bar{\alpha}\left(x^{\prime}+e_{H}\right) \\
& =\bar{\alpha}\left(x^{\prime}+e_{H}\right)-c_{H} \quad \text { by }(28) \\
& =b_{d}\left(x^{\prime}\right) .
\end{aligned}
$$

\footnotetext{
${ }^{21}$ Note, here we state the transfer as a payment from the agent to the principal, which is more natural there because in the debt contract the agent is the residual claimant.
} 
If $x^{\prime} \geq \min \left\{x_{0}, x_{d}\right\}$, the principal's payoff is the same as in the debt auction.

5) This stated direct mechanism can be implemented by a hybrid debt/share auction. There, bidders either submit a debt or a share bid, subject to two constraints: 1) the debt bid cannot be lower than $b_{d}\left(\min \left\{x_{0}, x_{d}\right\}\right)$, and 2) the share bid cannot be higher than $s_{H}\left(\min \left\{x_{0}, x_{d}\right\}\right)$. The principal selects the agent who submitted the highest debt bid as winner if at least one agent submitted a debt bid; otherwise, he selects the agent who submitted the highest share bid. The winner pays the second highest debt if at least two debt bids have been submitted; otherwise he pays either the highest share bid if exactly one debt bid was submitted or the second highest share if no one submitted a debt bid.

\section{Discussion}

Two limitation of the present analysis are that we assume binary effort choice and a particular additive production function.

Extending the model to include a larger set of effort choices does not seem to pose any particular problems. In particular, in our analysis of the different security bid auction we were careful not to use the binary effort assumption to allow the principal to infer the agent's effort choice.

If one employs a multiplicative production function, as in Kogan and Morgan (2010), the share auction exhibits different effort incentives. In particular, if the two share functions, $s_{L}, s_{H}$, intersect at all, their order is reversed, and low ability agents choose low and high ability agents high effort. However, as in our model, positive/negative cash rewards affect the region in which the agent chooses high effort in the same way. Therefore, the fine tuning of share auctions follows a similar pattern.

\section{A Appendix}

In this Appendix we fully explain and prove Proposition 7 in a sequence of Lemmas.

Because the game is symmetric (players' productivity parameters are i.i.d. random variables), we restrict attention to symmetric mechanisms with respect to the permutation of type profiles.

For convenience we define (and omit the subscripts in $T_{i}, Q_{i}$ ):

$$
t\left(x_{i}\right):=E_{x_{-i}}\left(T\left(x_{i}, x_{-i}\right)\right), \quad q\left(x_{i}\right):=E_{x_{-i}}\left(Q\left(x_{i}, x_{-i}\right)\right) .
$$

Define $\gamma\left(x_{i}, z_{i}\right)$ as the winner's cost of fulfilling his output requirement when the agent reports type $z_{i}$ while his true type is $x_{i}$, i.e.,

$$
\gamma\left(x_{i}, z_{i}\right)= \begin{cases}c_{L} & \text { if } \quad \psi\left(z_{i}\right) \leq x_{i}+e_{L} \\ c_{H} & \text { if } \quad x_{i}+e_{L}<\psi\left(z_{i}\right) \leq x_{i}+e_{H} \\ \infty & \text { otherwise. }\end{cases}
$$

We say that it is feasible for type $x_{i}$ to report $z_{i}$ if $\gamma\left(x_{i}, z_{i}\right)<\infty$. For convenience define

$$
U\left(x_{i}, z_{i}\right):=t\left(z_{i}\right)-q\left(z_{i}\right) \gamma\left(x_{i}, z_{i}\right) .
$$


A mechanism is truthfully implementable if it satisfies the output restriction (OR), is incentive compatible (IC), and satisfies individual rationality (IR):

$$
\begin{array}{lr}
\psi\left(x_{i}\right) \leq x_{i}+e_{H} & \text { for all } x_{i} \in[0,1] \\
U\left(x_{i}, x_{i}\right) \geq U\left(x_{i}, z_{i}\right) & \text { for all } x_{i}, z_{i} \in[0,1] \\
U\left(x_{i}, x_{i}\right) \geq 0 & \text { for all } x_{i} \in[0,1]
\end{array}
$$

Given two truthfully implementable mechanisms $(T, Q, \psi)$ and $(\hat{T}, Q, \hat{\psi})$, we say that $(\hat{T}, Q, \hat{\psi})$ improves upon $(T, Q, \psi)$ if $q(x) \hat{\psi}(x)-\hat{t}(x) \geq q(x) \psi(x)-t(x)$ for all $x \in[0,1]$ and $q(x) \hat{\psi}(x)-$ $\hat{t}(x)>q(x) \psi(x)-t(x)$ for some $x \in[0,1]$. The binary relation "improves upon" defined on the set of truthfully implementable mechanisms defines a partial ordering. Because we are looking for the optimal mechanism, we will focus on the maximal truthfully implementable mechanisms. In particular, maximal truthfully implementable mechanisms have the property that $\psi(x)$ is equal to either $x+e_{L}$ or $x+e_{H}$. The following two lemmas show that there is no loss of generality when we restrict our search for the optimal mechanism to the ones where $\psi(x)$ is equal to either $x+e_{L}$ or $x+e_{H}$.

Lemma A.1. Suppose that $(T, Q, \psi)$ is a truthfully implementable mechanism and $\psi\left(x^{\prime}\right)<x^{\prime}+e_{L}$ for some $x^{\prime}$. Define $\hat{\psi}$ by $\hat{\psi}(x)=\psi(x)$ for $x \neq x^{\prime}$ and $\hat{\psi}\left(x^{\prime}\right)=x^{\prime}+e_{L}$. Then $(T, Q, \hat{\psi})$ is truthfully implementable.

Proof. We only need to check (IC).

$$
\begin{aligned}
& \hat{U}\left(x^{\prime}, x^{\prime}\right)=t\left(x^{\prime}\right)-q\left(x^{\prime}\right) c_{L}=U\left(x^{\prime}, x^{\prime}\right) \geq U\left(x^{\prime}, x\right)=t(x)-q(x) \gamma\left(x^{\prime}, x\right)=\hat{U}\left(x^{\prime}, x\right), \\
& \hat{U}(x, x)=t(x)-q(x) \gamma(x, x)=U(x, x) \geq U\left(x, x^{\prime}\right)=t\left(x^{\prime}\right)-q\left(x^{\prime}\right) \gamma\left(x, x^{\prime}\right) \geq \hat{U}\left(x, x^{\prime}\right)
\end{aligned}
$$

The last inequality holds because $\hat{\gamma}\left(x, x^{\prime}\right) \geq \gamma\left(x, x^{\prime}\right)$, where $\hat{\gamma}(x, z)$ is the cost function A.2 with $\psi$ replaced by $\hat{\psi}$.

Lemma A.2. Suppose that $(T, Q, \psi)$ is a truthfully implementable mechanism and $x^{\prime}+e_{L}<$ $\psi\left(x^{\prime}\right)<x^{\prime}+e_{H}$ for some $x^{\prime}$. Define $\hat{\psi}$ by $\hat{\psi}(x)=\psi(x)$ for $x \neq x^{\prime}$ and $\hat{\psi}\left(x^{\prime}\right)=x^{\prime}+e_{H}$. Then $(T, Q, \hat{\psi})$ is truthfully implementable.

The proof is the same as that of the previous lemma. Hence we will focus on truthfully implementable mechanisms where $\psi(x)$ is equal to either $x+e_{L}$ or $x+e_{H}$. Define $X_{H}:=\{x \mid \psi(x)=$ $\left.x+e_{H}\right\}$ and $X_{L}:=\left\{x \mid \psi(x)=x+e_{L}\right\}$.

Lemma A.3. A maximal truthfully implementable mechanism $(T, Q, \psi)$ satisfies $\psi(x)=x+e_{H}$ for all $x \in(1-\Delta e, 1]$.

Proof. Suppose to the contrary that $\psi\left(x^{\prime}\right)=x^{\prime}+e_{L}$ for some $x^{\prime} \in(1-\Delta e, 1]$. Define $\hat{\psi}$ by $\hat{\psi}(x)=\psi(x)$ for $x \neq x^{\prime}$ and $\hat{\psi}\left(x^{\prime}\right)=x^{\prime}+e_{H}$ and $\hat{T}$ by $\hat{T}_{i}\left(x_{i}, x_{-i}\right)=T_{i}\left(x_{i}, x_{-i}\right)$ for $x_{i} \neq x^{\prime}$ and $\hat{T}_{i}\left(x^{\prime}, x_{-i}\right)=T_{i}\left(x^{\prime}, x_{-i}\right)+q\left(x^{\prime}\right) \Delta c$. Then $\hat{t}\left(x^{\prime}\right)=t\left(x^{\prime}\right)+q\left(x^{\prime}\right) \Delta c$ and $(\hat{T}, Q, \hat{\psi})$ is truthfully implementable as shown below. This contradicts the fact that $(T, Q, \psi)$ is a maximal truthfully implementable mechanism, because

$$
q(x) \hat{\psi}(x)-\hat{t}(x)=q(x)(\psi(x)+\Delta e)-(t(x)+q(x) \Delta c)>q(x) \psi(x)-t(x) .
$$


We now show that $(\hat{T}, Q, \hat{\psi})$ is truthfully implementable. It is obvious that (IR) holds for $(\hat{T}, Q, \hat{\psi})$. In checking the condition (IC), it is sufficient to check the condition for the types above $x^{\prime}$, because the types below $x^{\prime}$ cannot fulfill the output requirement.

$$
\hat{U}\left(x, x^{\prime}\right)=t\left(x^{\prime}\right)+q\left(x^{\prime}\right) \Delta c-q\left(x^{\prime}\right) c_{H}=t\left(x^{\prime}\right)-q\left(x^{\prime}\right) c_{L}=U\left(x, x^{\prime}\right) \leq U(x, x)=\hat{U}(x, x) .
$$

Lemma A.4. A mechanism $(T, Q, \psi)$ satisfies (IC) if and only if the following conditions hold:

i) $U(x, x)$ is non-decreasing in $x$

ii) $x \in X_{H}$ and $x^{\prime} \geq x+\Delta e \Rightarrow U\left(x^{\prime}, x^{\prime}\right) \geq U(x, x)+q(x) \Delta c$

iii) $x^{\prime} \in X_{L}$ and $x^{\prime} \in(x, x+\Delta e] \Rightarrow U\left(x^{\prime}, x^{\prime}\right) \leq U(x, x)+q\left(x^{\prime}\right) \Delta c$.

Proof. (1) Necessity: i) Due to the transitivity of the inequality, it is sufficient to show $U\left(x^{\prime}, x^{\prime}\right) \geq$ $U(x, x)$ for $x, x^{\prime}$ with $x^{\prime} \in(x, x+\Delta e]$. If $x \in X_{H}$, then $U\left(x^{\prime}, x^{\prime}\right) \geq U\left(x^{\prime}, x\right)=t(x)-q(x) c_{H}=U(x, x)$. If $x \in X_{L}$, then $U\left(x^{\prime}, x^{\prime}\right) \geq U\left(x^{\prime}, x\right)=t(x)-q(x) c_{L}=U(x, x)$.

ii) Suppose $x \in X_{H}$ and $x^{\prime} \geq x+\Delta e$. Then (IC) implies

$$
U\left(x^{\prime}, x^{\prime}\right) \geq U\left(x^{\prime}, x\right)=t(x)-q(x) c_{L}=U(x, x)+q(x) \Delta c .
$$

iii) Suppose $x^{\prime} \in X_{L}$ and $x^{\prime} \in(x, x+\Delta e)$. Then (IC) implies

$$
U(x, x) \geq U\left(x, x^{\prime}\right)=t\left(x^{\prime}\right)-q\left(x^{\prime}\right) c_{H}=U\left(x^{\prime}, x^{\prime}\right)-q\left(x^{\prime}\right) \Delta c .
$$

(2) Sufficiency: If $z \in X_{H}$ and $z \leq x-\Delta e$, then

$$
\left.U(x, z)=t(z)-q(z) c_{L}=U(z, z)+q(z) \Delta c \leq U(x, x) \text { by ii }\right) .
$$

If $z \in X_{H}$ and $z \in(x-\Delta e, x)$, then

$$
\left.U(x, z)=t(z)-q(z) c_{H}=U(z, z) \leq U(x, x) \text { by i }\right) .
$$

If $z \in X_{L}$ and $z<x$, then

$$
\left.U(x, z)=t(z)-q(z) c_{L}=U(z, z) \leq U(x, x) \text { by i }\right) .
$$

If $z \in X_{L}$ and $z \in(x, x+\Delta e)$, then

$$
U(x, z)=t(z)-q(z) c_{H}=U(z, z)-q(z) \Delta c \leq U(x, x) \text { by iii). }
$$

If either $z \in X_{L}$ and $z>x+\Delta e$ or $z \in X_{H}$ and $z>x$, then $U(x, z)=-\infty<U(x, x)$.

As long as the principal can extract the entire surplus, he prefers to assign high output, $x+e_{H}$, because $e_{H}-c_{H} \geq e_{L}-c_{L}$. Lemma A.3 shows that $(1-\Delta e, 1] \subset X_{H}$. The following lemma shows that the principal can fully extract the surplus when $X_{H}=(1-\Delta e, 1]$.

Lemma A.5. The principal can extract the entire surplus if $\psi(x)=x+e_{H}$ for $x \in(1-\Delta e, 1]$ and $\psi(x)=x+e_{L}$ for $x \in[0,1-\Delta e]$.

Proof. Consider the mechanism (16)-(18) for the particular choice of $\hat{x}=1-\Delta e$. Under this mechanism, $q(x)=G(x)$ and $t(x)=q(x) \gamma(x, x)$. Hence $U(x, x)=t(x)-q(x) \gamma(x, x)=0$ for all $x$, and thus (IR) is satisfied. Furthermore, (IC) is satisfied by Lemma A.4. Because it always selects the highest type, it maximizes the revenue among all truthful mechanisms with $X_{H}=(1-$ $\Delta e, 1]$. 
Note that the principal can extract the entire surplus with $X_{H}=[0,1]$ if $\Delta e>1$. Given $X_{H}=$ $(1-\Delta e, 1]$, the optimal selection rule is $Q$, because the output $\psi(x)$ is increasing in winner's type $x$, whereas the payment is already determined when agents report their types.

For an arbitrary $X_{H}$ define $\hat{x}:=\inf \left\{x \mid x \in X_{H}\right\}$. Define a function $u:[0,1] \rightarrow \mathbb{R}$ as follows: ${ }^{22}$

$$
u(x)= \begin{cases}0 & \text { if } x<\hat{x}+\Delta e \\ \sup \left\{u(y)+q(y) \Delta c \mathbb{1}_{X_{H}} \mid y \leq x-\Delta e, y \in X_{H}\right\} & \text { otherwise. }\end{cases}
$$

Also define

$$
t(x)=u(x)+G(x) \gamma(x, x) .
$$

Then, $U(x, x)=u(x)$ and the conditions in Lemma A.4 are satisfied. Furthermore, the payment is minimized for the given $X_{H}$.

Suppose $X_{H}=\left(x_{0}, 1\right]$ and consider increasing the size of the high effort region $X_{H}$ by a small interval so that the probability of high effort is increased by $\varepsilon>0$. In other words consider choosing $x^{\prime}$ and $\delta\left(x^{\prime}\right)$ so that $n \int_{x^{\prime}}^{x^{\prime}+\delta\left(x^{\prime}\right)} G(t) f(t) d t=F\left(x^{\prime}+\delta\left(x^{\prime}\right)\right)^{n}-F\left(x^{\prime}\right)^{n}=\varepsilon$ and that the new high effort region becomes $X_{H}^{\prime}=\left[x^{\prime}, x^{\prime}+\delta\left(x^{\prime}\right)\right] \cup X_{H}$. We now show that it is most profitable to increase $X_{H}$ from the top so that $X_{H}^{\prime}=\left[x^{\prime}, 1\right]$.

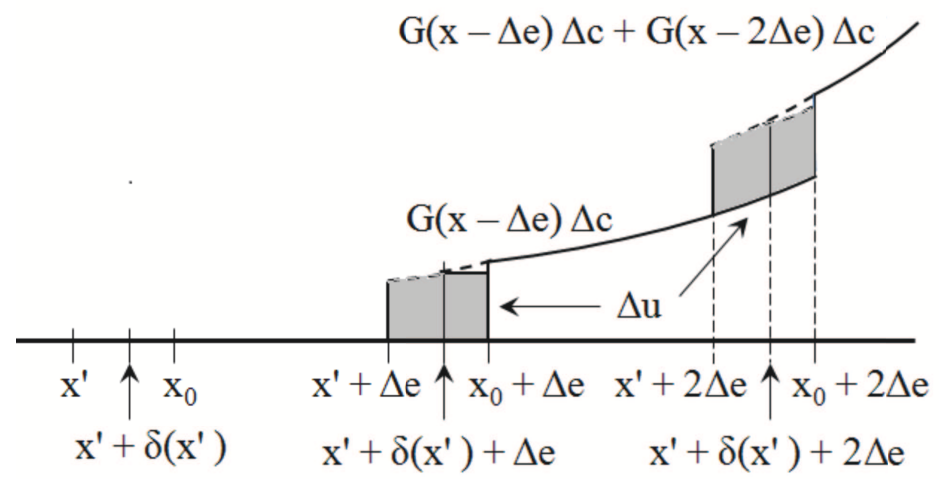

Figure 2: Increase in payment due to increase in $X_{H}$

Because the principal's expected revenue is $\Pi=n \int_{0}^{1}(G(x) \psi(x)-t(x)) f(x) d x$, the change in the principal's expected revenue due to change in $X_{H}$ is:

$$
\begin{aligned}
\Delta \Pi & =n \int_{x^{\prime}}^{x^{\prime}+\delta\left(x^{\prime}\right)} G(x)(\Delta e-\Delta c) f(x) d x-n \int_{0}^{1} \Delta u(x) f(x) d x \\
& =\varepsilon(\Delta e-\Delta c)-n \int_{0}^{1} \Delta u(x) f(x) d x .
\end{aligned}
$$

Hence, $x^{\prime}$ and $\delta\left(x^{\prime}\right)$ should be chosen to minimize $\int_{0}^{1} \Delta u(x) f(x) d x$. A particular choice of $x^{\prime}$ (and $\delta\left(x^{\prime}\right)$ ) is drawn in Figure 2. In this graph $x^{\prime}$ is chosen slightly away from the top. Because $\left(x^{\prime}+\delta\left(x^{\prime}\right), x_{0}\right] \subset X_{L}$, the graph of $u(x)$ on the interval $\left(x^{\prime}+\delta\left(x^{\prime}\right)+\Delta e, x_{0}+\Delta e\right]$ is flat. On this interval, $\Delta u(x)$ is smaller compared to the case where $x^{\prime}$ is chosen at the top. On the other hand, $\Delta u(x)$ is larger on the interval starting from $x^{\prime}$ compared to the case where $x^{\prime}$ is chosen at the top. In fact, $\Delta u(x)=G(x)$ on this interval, and the interval on which the difference between the

\footnotetext{
${ }^{22}$ The value of $u$ for larger $x$ is defined by that for smaller $x$.
} 
two $\Delta u(x)$ 's is $G(x)$ is larger when $x^{\prime}+\delta\left(x^{\prime}\right)$ is farther away from $x_{0}$. Hence, $\int_{0}^{1} \Delta u(x) f(x) d x$ is minimized when $x^{\prime}$ is chosen at the top. ${ }^{23}$

Therefore, the set $X_{H}$ is the interval $[\hat{x}, 1]$, and the function $u(x)$ can be stated explicitly as in equation (19).

This completes the proof.

\section{References}

Abhishek, V., Hajek, B., Williams, S. R., 2013. On bidding with securities: Risk aversion and positive dependence. Discussion paper, University of Illinois.

Board, S., 2007. Selling options. Journal of Economic Theory 136, 324-340.

Boyle, C. E., 2005. Swiss Re to acquire GE Insurance Solutions for $\$ 6.8$ billion. Insurance Journal, Dec. 5.

Che, Y.-K., Kim, J., 2010. Bidding with securities: Comment. American Economic Review 100, 1929-1935.

Crémer, J., 1987. Auctions with contingent payments: Comment. American Economic Review 77, 746.

DeMarzo, P., Kremer, I., Skrzypacz, A., 2005. Bidding with securities: Auctions and security design. American Economic Review 95, 936-959.

Hansen, R. G., 1985. Auctions with contingent payments. American Economic Review 75, 862865.

Holmstrœm, B., 1979. Moral hazard and observability. Bell Journal of Economics 10, 74-91.

Innes, R., 1990. Limited liability and incentive contracting with ex ante choices. Journal of Economic Theory 52, 45-67.

Kogan, S., Morgan, J., 2010. Securities auctions under moral hazard: An experimental study. Review of Finance 14 (3), 477-520s.

Laffont, J.-J., Tirole, J., 1987. Auctioning incentive contracts. Journal of Political Economy 95, 921-937.

McAfee, R., McMillan, J., 1987. Competition for agency contracts. RAND Journal of Economics 18, 296-307.

Milgrom, P. R., 1987. Auction theory. In: Bewley, T. F. (Ed.), Advances in Economic Theory. Econometric Society Monographs No. 12, Cambridge University Press, Cambridge, pp. 1-32.

Myerson, R. B., 1981. Optimal auction design. Mathematics of Operations Research 6, 58-73.

Rhodes-Kropf, M., Viswanathan, S., 2005. Financing auction bids. RAND Journal of Economics 36, 789-815.

\footnotetext{
${ }^{23}$ Cases not explained by the picture is the cases where $x^{\prime}$ is close to 0 . In these cases $u(x) \geq G\left(x^{\prime}+\delta\left(x^{\prime}\right)\right) \Delta c \geq \varepsilon / \varepsilon^{1 / n}$ for $x \geq x^{\prime}+\delta\left(x^{\prime}\right)$, which is larger relative to $\varepsilon$ when $\varepsilon$ is small. Thus these cases are also dominated by $x^{\prime}$ chosen at the top.
} 
Samuelson, W., 1987. Auctions with contingent payments: Comment. American Economic Review 77, 740-745.

Skrzypacz, A., 2013. Auctions with contingent payments - an overview. International Journal of Industrial Organization, forthcoming. 